\title{
Enhancement of interfacial properties of basalt fiber reinforced nylon 6 matrix composites with silane coupling agents
}

\author{
T. Deák ${ }^{1}$, T. Czigány*1, P. Tamás ${ }^{1}$, Cs. Németh ${ }^{2}$ \\ ${ }^{1}$ Department of Polymer Engineering, Budapest University of Technology and Economics, Múegyetem rkp. 3., H-1111 \\ Budapest, Hungary \\ ${ }^{2}$ Chemical Research Center, Hungarian Academy of Sciences, Pusztaszeri út 59-67., H-1025 Budapest, Hungary
}

Received 30 April 2010; accepted in revised form 31 May 2010

\begin{abstract}
In this work solution surface treatment was applied for producing basalt fiber reinforced PA6 matrix composites. Beyond scanning electron microscopy, static and dynamic mechanical tests, dynamic mechanical analysis of composites was used for qualifying the interfacial adhesion in a wide temperature range. The loss factor peak height of loss factor is particularly important, because it is in close relationship with the mobility of polymer molecular chain segments and side groups, hence it correlates with the number and strength of primary or secondary bondings established between the matrix and the basalt fibers. It was proven, that the interfacial adhesion between basalt fibers and polyamide can be largely improved by the application of silane coupling agents in the entire usage temperature range of composites. The presence of coupling agents on the surface of basalt fibers was proven by Fourier transform infrared spectroscopy. The best results were obtained by 3-glycidoxypropyltrimethoxysilane coupling agent.
\end{abstract}

Keywords: polymer composites, adhesion, basalt fibers

\section{Introduction}

Thermoplastic matrix composites have gained great importance in the last 30 years. The most common processing technology of thermoplastic matrix composites is injection molding, which is capable of fabricating products in large quantities with good dimensional accuracy and complex geometry. In the last two decades, due to their good properties, basalt fibers (BF) have come into consideration as potential reinforcement of composite materials. Basalt fibers are incombustible, chemically inert, environmentally and ecologically harmless, and free of carcinogens and other health hazards. Basalt fibers have been comprehensively investigated as reinforcement of polypropylene (PP) matrix composites $[1,2]$. Polyamide (PA) has been seldom used for this purpose, although it promises better results, because PA and basalt both have polar chemical structure, thus presumably it is easier to promote proper interface adhesion between the fibers and the matrix. It must be also noted that polyamides have better mechanical properties and higher heat resistance than polypropylene [3-7]. Glass fiber reinforced PA is a vital engineering material in automotive and other industries today. Most car manufacturers employ glass fiber reinforced PA intake manifolds and sumps in their engines. One of the most significant problems of injection molded composites is the formation of proper interfacial adhesion between the matrix and the fibers. It is particularly relevant because during processing the strong shearing stresses reduce the 
length of basalt and glass fibers to the order of magnitude of a few tenths millimeters, regardless of their original size. Thus the critical fiber length must be decreased by promoting the interfacial adhesion. In case of BF reinforced PA composites the technology of surface treatment must be developed in order to get composite materials which are comparable with glass fiber reinforced ones. The experiences gained with glass fibers can be used as basis due to the nearly same structure and similar chemical composition of basalt and glass fibers [8]. The most effective way of the enhancement of interfaces in composites is the establishment of strong chemical bonds between the matrix and the fibers. The most common and efficient coupling agents for PA-glass fiber systems are the various silane compounds. The structure of silane molecules is the following: $\mathrm{R}-\mathrm{SiX} \mathrm{X}_{3}$ or $\mathrm{R}-\left(\mathrm{CH}_{2}\right)_{\mathrm{n}}-\mathrm{SiX} \mathrm{X}_{3}$. One side of the molecule establishes bond with the surface of the fiber while the other end of the molecule establishes bond with the matrix (Figure 1.). $X$ is a hydrolyzable ethoxy $\left(-\mathrm{OCH}_{2} \mathrm{CH}_{3}\right)$ or methoxy $\left(-\mathrm{OCH}_{3}\right)$ group, which transforms in water solution through hydrolysis (Figure 1a). Trihydroxysilane is formed during hydrolysis, which develops covalent or hydrogen bonds with the hydroxyl groups on the surface of basalt or glass fibers (Figure 1b). When the fibers are dried, a reversible condensation occurs between the silane molecules and the fiber and between the neighboring silane molecules, forming a polysiloxane layer (Figure 1c). The $R$ groups establish bonds with the reactive side groups of the polymer matrix [9-11]. Silane and titanate coupling agents are applied on the surface of fibers during fiber manufacturing. In the industry coupling agents are only one of many components of sizings $[2,8,12,13]$. Further functions of sizing are protection of fibers, assuring processability and enhancing interfacial adhesion. The currently available continuous basalt fibers are covered with sizings optimized for epoxy, vinylester and polyester resins [9-14]. The methods of enhancing interfacial properties of PP-basalt composites are worked out [15-18], while it is still necessary to find the appropriate technology for PA matrix composites. Probably the coupling agents developed for glass fiber reinforced composites are applicable for $\mathrm{BF}$, due to the similarities between the structure and chemical composition of basalt and glass fibers [19, 20]. The aim of this work was to determine the applicability of silane coupling agents generally applied for glass fiber reinforced PA matrix composites in case of BF. The dependence of properties of composites on the type and amount of silanes was also studied.

\section{Experimental}

\subsection{Materials}

In our experiments the original sizing of basalt fibers - applied by the manufacturer - was removed and a new coupling agent was applied, by immersing the fiber in the solution of coupling agent and subsequent drying. This enables the formation of a coating of coupling agent, although we must lack those components of the sizing which have other functions, e.g. the film former. In the first step silane coupling agents with different functional groups were employed (Table 1). Coupling agents

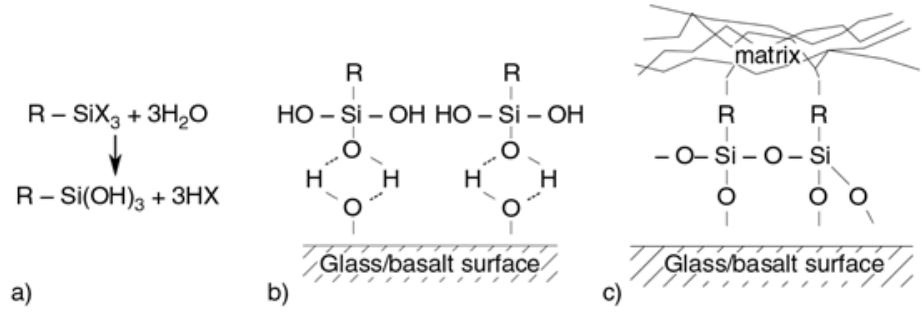

Figure 1. Steps of application of silane coupling agents: hydrolysis (a), formation of bonds between the glass fiber surface and silane (b), polysiloxane (c)

Table 1. Data of used silane coupling agents

\begin{tabular}{|l|l|l|c|}
\hline \multicolumn{1}{|c|}{ Manufacturer } & Name & \multicolumn{1}{c|}{ Type } & Structure \\
\hline Wacker Chemie AG & GF80 & 3-Glycidoxypropyltrimethoxysilane & O \\
& & & $\begin{array}{c}\text { I } \\
\left(\mathrm{CH}_{3} \mathrm{O}\right)_{3} \mathrm{SiC}_{3} \mathrm{H}_{6} \mathrm{OCH}_{2} \mathrm{CH}_{-} \mathrm{CH}_{2}\end{array}$ \\
\hline Wacker Chemie AG & GF91 & N-(2-Aminoethyl)-3-aminopropyltrimethoxysilane & $\left(\mathrm{CH}_{3} \mathrm{O}\right)_{3} \mathrm{C}_{3} \mathrm{H}_{6} \mathrm{NHC}_{2} \mathrm{H}_{4} \mathrm{NH}_{2}$ \\
\hline Wacker Chemie AG & GF93 & 3-Aminopropyltriethoxysilane & $\left(\mathrm{C}_{2} \mathrm{H}_{5} \mathrm{O}\right)_{3} \mathrm{SiC}_{3} \mathrm{H}_{6} \mathrm{NH}_{2}$ \\
\hline
\end{tabular}


were supplied by Wacker Chemie AG (Burghausen, Germany). These silanes were selected from the types which are most commonly used for glass fiber reinforced composites. The most appropriate of these was selected by comparing the basic mechanical properties of composites. The amount of coupling agents is an important parameter [21], hence further investigations were necessary to assess the effect of coupling agent concentration of composite properties. The above mentioned $\mathrm{BF}$ reinforced composites were made with 30 weight $\%$ (wt \%) fiber content, because for glass fiber reinforced composites this is the most common fiber content. Finally composites were made with different fiber contents. The effectiveness of silane coupling agents was evaluated by the basic static and dynamic mechanical properties of composites and Scanning Electron Microscope (SEM) micrographs, made with a Jeol (Tokyo, Japan) JSM-6380LA instrument.

The matrix was Schulamid 6MV13F polyamide 6 (PA6) from A. Schulman AG (Kerpen, Germany). Basalt fibers were type BCS 13.6 made by Kamenny Vek company (Moscow, Russia). The fibers have an average diameter of $14.2 \pm 1.4 \mu \mathrm{m}$ and are cut to a length of $6 \mathrm{~mm}$. The original sizing was removed by annealing at $400^{\circ} \mathrm{C}$ for 3 hours. The coupling agents were dissolved in distilled water. Initially the amount of silanes was $1 \mathrm{wt} \%$ in the ratio of BF. The basalt fibers were immersed in the solution for 2 hours, after dissolving for 2 hours in order to effectuate the hydrolysis of silanes and their bonding with the hydroxyl groups on the surface of BF. The water was evaporated at $80^{\circ} \mathrm{C}$ in an air circulating oven. The composites were compounded by a Brabender (Duisburg, Germany) Plasti-Corder PL 2100 twin screw extruder at $255^{\circ} \mathrm{C}$ and $10 \mathrm{~min}^{-1}$ screw rotational speed, afterwards they were granulated. Standard dumbbell specimens with $4 \times 10 \mathrm{~mm}$ cross section were made with an Arburg (Lossburg, Germany) 270 C 500-250 injection molding machine at $270^{\circ} \mathrm{C}$.

\subsection{Methods}

Tensile tests were performed according to the EN ISO 527 standard on a Zwick (Ulm, Germany) Z020 universal testing machine. The gauge length was $100 \mathrm{~mm}$, the test speed was $2 \mathrm{~mm} / \mathrm{min}$. Elongation was monitored by video extensometer. The
3 point bending tests were performed according to the EN ISO 178 standard. The span length was $64 \mathrm{~mm}$, the test speed was $2 \mathrm{~mm} / \mathrm{min}$. Charpy impact tests were performed according to the EN ISO 179 standard with a CEAST (Pianezza, Italy) Resil Impactor instrument, using notched and unnotched specimens. The notch was 'A' type, with $0.25 \mathrm{~mm}$ notch tip radius, $45^{\circ}$ angle and $2 \mathrm{~mm}$ depth. The cross section of the specimens was $4 \times 10 \mathrm{~mm}$, while the span length was $62 \mathrm{~mm}$. The energy absorbed by the specimen was registrated during test and impact strengths $\alpha_{c U}$ for unnotched and $\alpha_{c N}$ for notched specimens) were calculated with Equation (1):

$$
\alpha_{c}=\frac{E_{C}}{h \cdot w} \cdot 10^{3}
$$

where $E_{C}$ is the energy absorbed by the specimen, $h$ is the thickness and $w$ is the width of the specimen (in case of notched specimens $w$ is the residual width). Dynamic Mechanical Analysis (DMA) tests were performed with specimens machined from the injection molded tensile specimens. Tests were executed with dual cantilever configuration and force control (the force amplitude was $400 \mathrm{~N}$ ) on a Perkin-Elmer (Covina, USA) Diamond DMA instrument from -40 to $180^{\circ} \mathrm{C}$. The cross section of specimens was $2 \times 4 \mathrm{~mm}$, the frequency was $1 \mathrm{~Hz}$. The span length was $30 \mathrm{~mm}$. The heating rate was $2^{\circ} \mathrm{C} / \mathrm{min}$. The surfaces of basalt fibers with different coatings were examined with Fourier transform infrared spectroscopy (FTIR). Tests were performed with a Varian (Palo Alto, USA) Scimitar 2000 instrument. Here the sample is pressed between a diamond and a sapphire. The sample is illuminated through the diamond with infrared light in the wavenumber range between 400 and $4000 \mathrm{~cm}^{-1}$. The reflected light arrives to the spectrometer through the same diamond. The applied samples were bunches of $6 \mathrm{~mm}$ long chopped BF. This method is capable of detecting the presence of coupling agents on the surface of BF through identifying atom groups of the silane compounds. Quantitative examination is restrictedly possible by this technique. The residual fiber length in the injection molded specimens was determined in the following way: pieces cut from the middle section of dumbbell specimens were calcinated in ceramic pots with gas flame and in electric oven at $500^{\circ} \mathrm{C}$. The fibers were spread on glass slides using formic acid 
as carrier fluid. The length of fibers was measured with an Olympus (Tokyo, Japan) BX51 optical microscope and analySIS Steel Factory image analysis program, employing through lighting and magnification of 10 . The length of 500 fibers was measured from each sample.

\section{Results and discussion}

The first step was the selection of the most adequate coupling agent. Composites were made with $30 \mathrm{wt} \%$ fiber content with fibers treated with the coupling agents shown in Table 1. Mechanical tests were performed according to the previous chapter. The results are shown in Table 2. The composites made with GF80, GF91 and GF93 coupling agents have approximately identical mechanical properties. Considering the results, GF80 coupling agent

Table 2. Mechanical properties of PA6 composites reinforced with basalt fibers treated with different coupling agents

\begin{tabular}{|l|c|c|c|}
\hline \multirow{2}{*}{} & \multicolumn{3}{|c|}{ Type of sizing } \\
\cline { 2 - 4 } & GF80 & GF91 & GF93 \\
\hline Tensile strength, $\sigma_{M}[\mathrm{MPa}]$ & $114.4 \pm 0.2$ & $115.2 \pm 0.5$ & $113.3 \pm 0.3$ \\
\hline Tensile modulus, $E[\mathrm{MPa}]$ & $7564 \pm 228$ & $7296 \pm 287$ & $7669 \pm 205$ \\
\hline Flexural strength, $\sigma_{f M}[\mathrm{MPa}]$ & $159.7 \pm 0.7$ & $161.7 \pm 0.5$ & $160.4 \pm 1.1$ \\
\hline Flexural modulus, $E_{f}[\mathrm{MPa}]$ & $5963 \pm 35$ & $5689 \pm 14$ & $5656 \pm 23$ \\
\hline$\alpha_{c N}\left[\mathrm{~kJ} / \mathrm{m}^{2}\right]$ & $10.1 \pm 0.5$ & $9.7 \pm 0.3$ & $9.6 \pm 1.0$ \\
\hline$\alpha_{c U}\left[\mathrm{~kJ} / \mathrm{m}^{2}\right]$ & $82.4 \pm 6.1$ & $83.3 \pm 2.6$ & $71.3 \pm 6.4$ \\
\hline
\end{tabular}

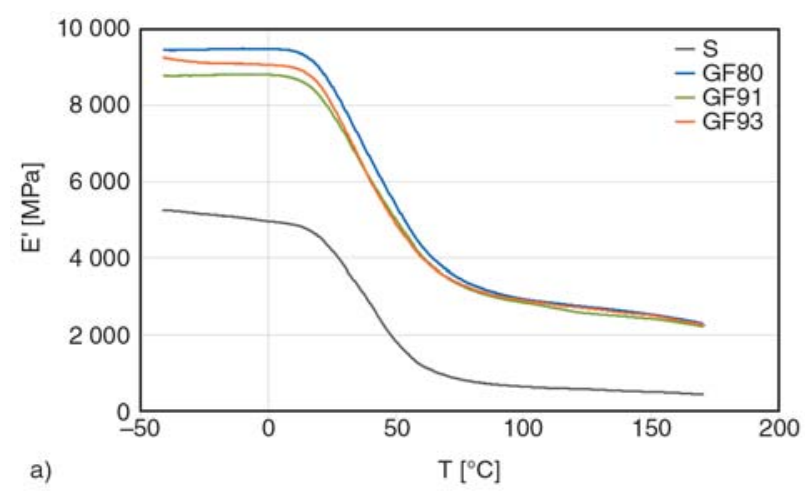

was chosen for further work because it had the most favorable combination of properties. Figure 2. shows the curves obtained from DMA tests of composites with different types of coupling agents. Neat matrix is denoted by $S$. According to Figure 2, there are very small differences between the DMA curves of composites treated with different coupling agents. This is in accordance with Table 2, where tensile and flexural moduli relate to each other similarly. The amount of coupling agents is a key parameter for solution treatment of fibers. Hence further investigations were needed to determine the effect of solution concentration using the GF80 coupling agent selected previously. The applied concentrations were $0.5,1,2$ and $4 \mathrm{wt} \%$ in ratio of basalt fibers. The optimal concentration was chosen by comparing the basic mechanical properties of composites. The results of mechanical tests are shown in Table 3. It can be seen in Table 3 that all mechanical properties show some form of saturation: the properties seem to approach a limit value with increasing silane concentration. It is obvious that the optimal properties were not reached within the given limits, but the further augmentation of silane concentration would be uneconomical due to the high price of silanes. Finally it can be concluded that among the investigated materials the best composite properties can be reached

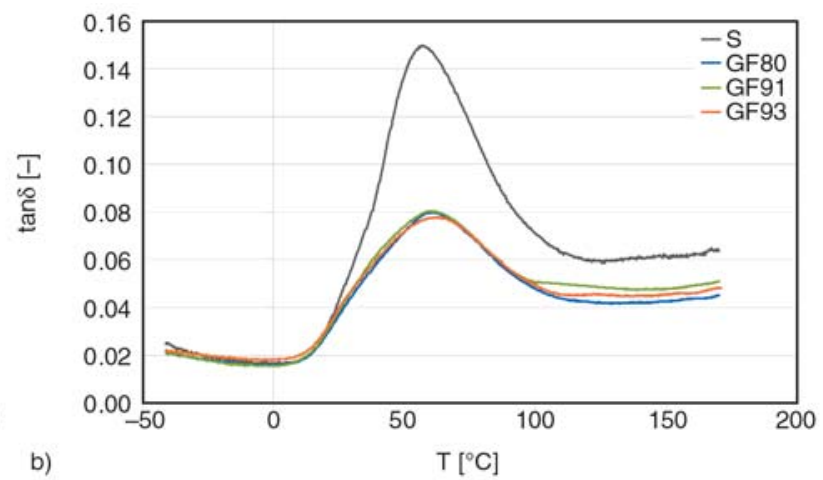

Figure 2. DMA curves of composites with different types of coupling agents ( $E^{\prime}$ : storage modulus, tan $\delta$ : loss factor)

Table 3. Mechanical properties of PA6 composites reinforced with basalt fibers treated with GF80 coupling agent at different concentrations

\begin{tabular}{|c|c|c|c|c|}
\hline & \multicolumn{4}{|c|}{ Concentration of sizing } \\
\hline & GF80 0.5\% & GF80 1\% & GF80 2\% & GF80 4\% \\
\hline Tensile strength, $\sigma_{M}[\mathrm{MPa}]$ & $108.4 \pm 0.1$ & $113.2 \pm 1.3$ & $119.0 \pm 0.5$ & $120.0 \pm 1.1$ \\
\hline Tensile modulus, $E$ [MPa] & $7337 \pm 70$ & $7564 \pm 228$ & $7673 \pm 141$ & $7789 \pm 210$ \\
\hline Flexural strength, $\sigma_{f M}[\mathrm{MPa}]$ & $155.2 \pm 1.2$ & $162.7 \pm 0.5$ & $167.6 \pm 0.2$ & $170.8 \pm 1.4$ \\
\hline Flexural modulus, $E_{f}[\mathrm{MPa}]$ & $5685 \pm 7$ & $5936 \pm 35$ & $5996 \pm 21$ & $6065 \pm 15$ \\
\hline$\alpha_{c N}\left[\mathrm{~kJ} / \mathrm{m}^{2}\right]$ & $9.3 \pm 0.8$ & $10.1 \pm 0.5$ & $11.3 \pm 12.7$ & $12.7 \pm 0.4$ \\
\hline$\alpha_{c U}\left[\mathrm{~kJ} / \mathrm{m}^{2}\right]$ & $66.8 \pm 3.5$ & $82.4 \pm 6.1$ & $86.0 \pm 2.8$ & $88.4 \pm 8.2$ \\
\hline
\end{tabular}




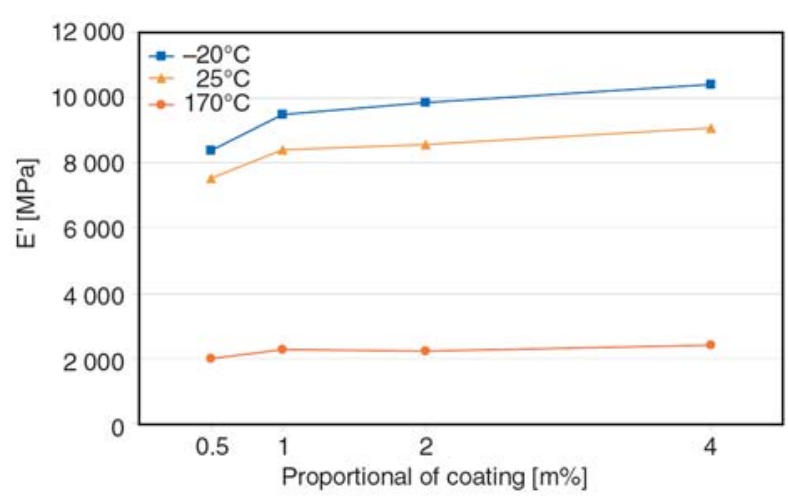

Figure 3. Storage moduli of composites with GF80 coupling agent at $-20,25$ and $170^{\circ} \mathrm{C}$ temperature as the function of proportion of coating correlated to basalt fibers

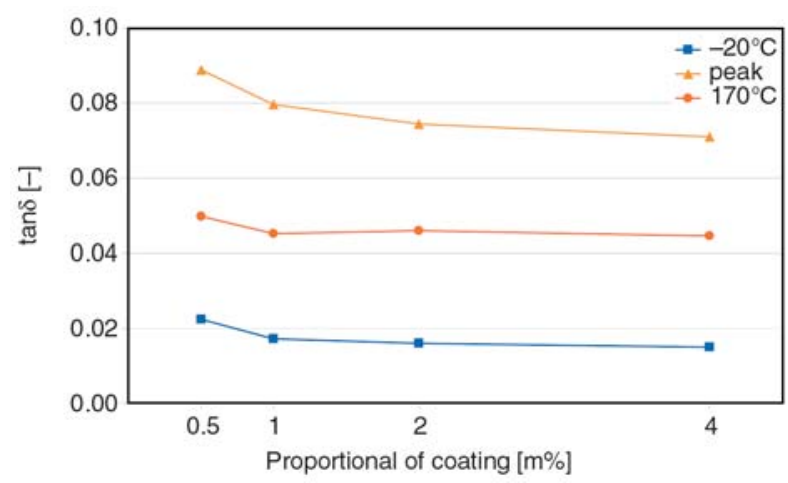

Figure 4. Loss factors of composites with GF80 coupling agent at -20 and $170^{\circ} \mathrm{C}$ and at the curve peak as the function of proportion of coating correlated to basalt fibers

with GF80 3-glycidoxypropyltrimethoxysilane applied on basalt fibers in a $4 \mathrm{wt} \%$ ratio. Figures 3 and 4 show the results of DMA tests of composites with GF80 coupling agent as the function of proportion of coating correlated to BF. In order to make results more expressive, storage modulus $\left(E^{\prime}\right)$ and loss factor $(\tan \delta)$ values are represented as the function of silane concentration and fiber content. Since this mode of representation does not allow us to use a continuous temperature range, 3 allotted temperatures were chosen for the diagrams: $-20,25$ and $170^{\circ} \mathrm{C}$ for the storage modulus. Loss factors were outlined at -20 , and $170^{\circ} \mathrm{C}$, and at the temperature of the $\tan \delta$ curve peak. The height of $\tan \delta$ curve peak is in close relationship with the mobility of polymer molecular chain segments and side groups, hence it correlates with the number and strength of primary or secondary bondings established between the matrix and the BF. The growth of $E^{\prime}$ with increasing silane concentration is corresponding with Table 3 . The loss factor is decreasing with growing silane concentration, but it also shows saturation, approaching a limit value. It can be concluded from Figures 3 and 4 that the tan $\delta$ peak is very sensitive to the strength of interfacial adhesion, but storage modulus also shows the differences at other temperatures. The next step was to evaluate the applicability of this surface treatment for composites with different fiber contents. Composites were made with $10,20,30$ and $40 \mathrm{wt} \% \mathrm{BF}$ content. Fibers were coated with 4 wt $\%$ GF80 silane coupling agents (marking: GF80). For comparison composites also were made with untreated BF (marking: SN). The results of mechanical tests are shown in Table 4. Unnotched neat PA6 specimens were not broken during Charpy tests, therefore only the impact strengths of composites are shown in the last line of Table 4 . Table 5 shows the residual fiber lengths in the injection molded dumbbell specimens. It can be seen in Table 4 that coupling agents considerably improve the static mechanical properties of composites. The tensile strength is increased by $40 \%$, while flexural

Table 4. Mechanical properties of PA6 composites reinforced with untreated and 4 wt $\%$ GF80 silane coated basalt fibers

\begin{tabular}{|c|c|c|c|c|c|c|}
\hline & \multirow{2}{*}{ Sizing } & \multicolumn{5}{|c|}{ Fiber content } \\
\hline & & 0 wt \% & $10 \mathrm{wt} \%$ & 20 wt $\%$ & $30 \mathrm{wt} \%$ & $40 \mathrm{wt} \%$ \\
\hline \multirow{2}{*}{ Tensile strength, $\sigma_{M}[\mathrm{MPa}]$} & GF80 & \multirow{2}{*}{$57.8 \pm 0.3$} & $80.5 \pm 0.3$ & $100.0 \pm 4.0$ & $120.0 \pm 1.1$ & $128.4 \pm 1.4$ \\
\hline & $\mathrm{SN}$ & & $63.7 \pm 0.1$ & $71.3 \pm 1.2$ & $84.2 \pm 0.2$ & $86.9 \pm 0.1$ \\
\hline \multirow{2}{*}{ Tensile modulus, $E$ [MPa] } & GF80 & \multirow{2}{*}{$2669 \pm 180$} & $3903 \pm 81$ & $4849 \pm 552$ & $7789 \pm 210$ & $9904 \pm 403$ \\
\hline & $\mathrm{SN}$ & & $3529 \pm 251$ & $5172 \pm 209$ & $7529 \pm 375$ & $8756 \pm 266$ \\
\hline \multirow{2}{*}{ Flexural strength, $\sigma_{f M}[\mathrm{MPa}]$} & GF80 & \multirow{2}{*}{$61.0 \pm 0.5$} & $92.4 \pm 0.8$ & $122.8 \pm 0.4$ & $170.3 \pm 2.1$ & $182.5 \pm 1.5$ \\
\hline & $\mathrm{SN}$ & & $84.1 \pm 1.5$ & $103.9 \pm 2.2$ & $124.7 \pm 0.2$ & $129.8 \pm 0.2$ \\
\hline \multirow{2}{*}{ Flexural modulus, $E_{f}[\mathrm{MPa}]$} & GF80 & \multirow{2}{*}{$1790 \pm 7$} & $2834 \pm 34$ & $4090 \pm 14$ & $6065 \pm 15$ & $7223 \pm 64$ \\
\hline & $\mathrm{SN}$ & & $2741 \pm 92$ & $3847 \pm 118$ & $6184 \pm 33$ & $7717 \pm 22$ \\
\hline \multirow{2}{*}{$\alpha_{c N}\left[\mathrm{~kJ} / \mathrm{m}^{2}\right]$} & GF80 & \multirow{2}{*}{$21.7 \pm 0.6$} & $6.8 \pm 0.5$ & $6.8 \pm 1.2$ & $12.7 \pm 0.4$ & $12.8 \pm 1.2$ \\
\hline & $\mathrm{SN}$ & & $4.4 \pm 0.5$ & $5.3 \pm 0.4$ & $5.6 \pm 0.7$ & $7.2 \pm 0.7$ \\
\hline \multirow{2}{*}{$\alpha_{c U}\left[\mathrm{~kJ} / \mathrm{m}^{2}\right]$} & GF80 & \multirow[b]{2}{*}{-} & $37.5 \pm 4.0$ & $37.9 \pm 5.1$ & $88.4 \pm 8.2$ & $88.9 \pm 2.2$ \\
\hline & $\mathrm{SN}$ & & $20.3 \pm 0.1$ & $22.3 \pm 0.3$ & $27.3 \pm 0.3$ & $31.1 \pm 0.3$ \\
\hline
\end{tabular}


Table 5. Residual fiber length $[\mu \mathrm{m}]$ in injection molded specimens as the function of fiber content

\begin{tabular}{|c|c|c|}
\hline \multirow{2}{*}{$\begin{array}{c}\text { Fiber content } \\
\text { [wt } \% \text { ] }\end{array}$} & \multicolumn{2}{|c|}{ Sizing } \\
\cline { 2 - 3 } & $\mathbf{G F 8 0}$ & SN \\
\hline 10 & $0.224 \pm 0.161$ & $0.208 \pm 0.119$ \\
\hline 20 & $0.217 \pm 0.166$ & $0.201 \pm 0.129$ \\
\hline 30 & $0.189 \pm 0.132$ & $0.183 \pm 0.097$ \\
\hline 40 & $0.157 \pm 0.110$ & $0.152 \pm 0.102$ \\
\hline
\end{tabular}

strength is improved by $30 \%$ by the surface treatment. At the same time moduli practically were not influenced by the coupling agent. Fiber reinforcement decreases the impact strength compared to the matrix, but adding more fibers to the system causes the gradual growth of impact strength. It can be ascribed to the fact that basalt fibers increase the stiffness and rigidity of the composite, thus causing a decline of impact resistance, and can work as starting point of cracks. However, if the amount of reinforcing fiber grows considerably, the fibers rather stop crack propagation, which leads to a higher impact strength. Fiber surface treatment increased the impact strength with 100 to $200 \%$.

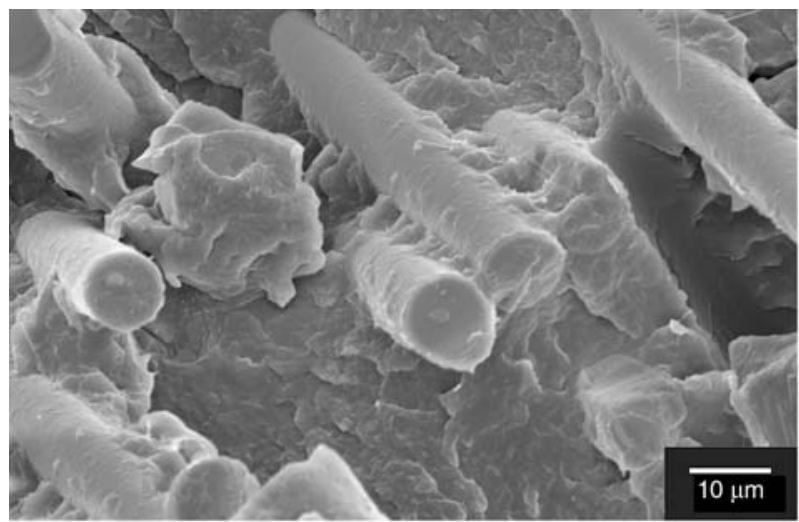

a)
Table 5 shows that during processing (compounding, grinding and injection molding) the basalt fibers are fragmented to an average length around 0.15 to $0.20 \mathrm{~mm}$. The average length decreases nearly linearly with increasing fiber content, and no remarkable difference can be found between sized and unsized fibers. Scanning electron micrographs of the fracture surfaces of tensile specimens are shown in Figure 5. It can be seen in Figure 5 that a thick layer of matrix material evolves on the surface of silane coated BF during fracture. It shows excellent interfacial strength, which means that fracture occurs rather in the matrix and not on the interface, which is reinforced by primary bondings. At the same time the surface of untreated BF completely disengages from the matrix. It shows that if there is any adhesion between the fibers and the matrix, it is much weaker than the shear strength of the matrix. Figures 6 to 8 show the results of DMA tests of composites with GF80 coupling agents at different fiber contents. It can be seen in Figures 6 and 7 that fiber content strongly influences $E^{\prime}$. The

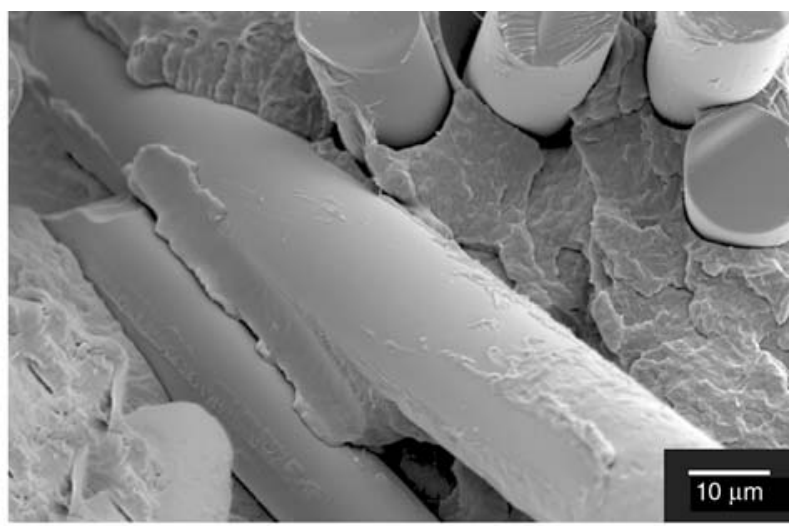

b)

Figure 5. SEM micrographs of fracture surfaces of tensile specimens of composites, a: with 4 wt $\%$ GF80 silane coupling agent, b: unsized fibers
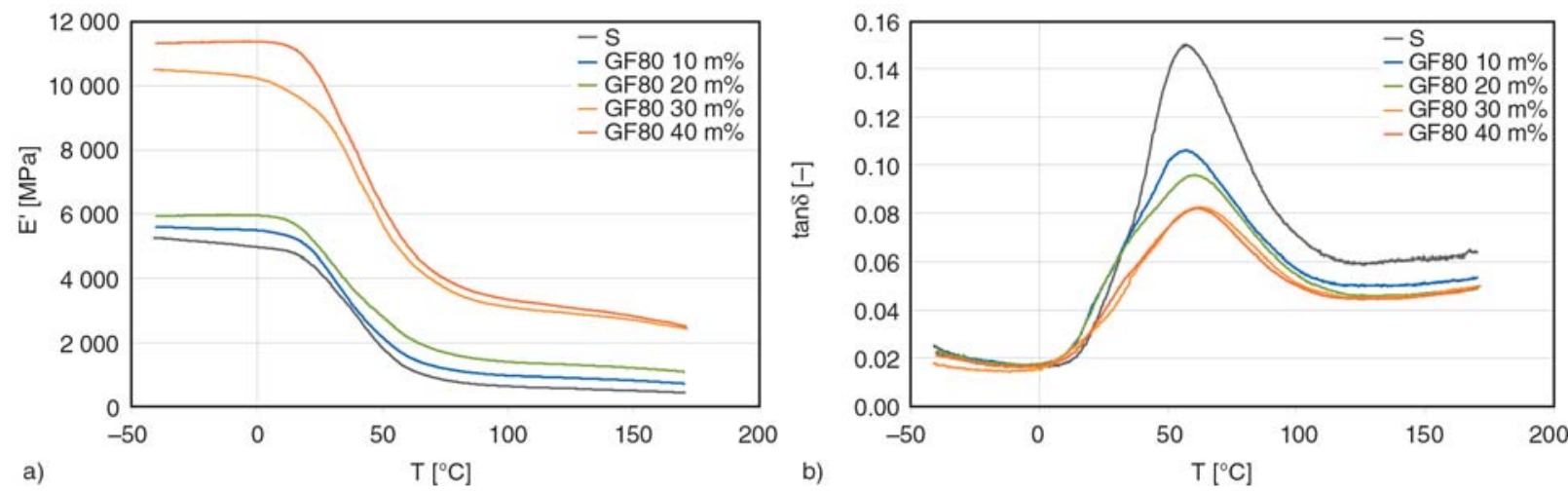

Figure 6. DMA curves of composites with GF80 coupling agent at different fiber contents ( $E^{\prime}$ : storage modulus, tan $\delta$ : loss factor) 


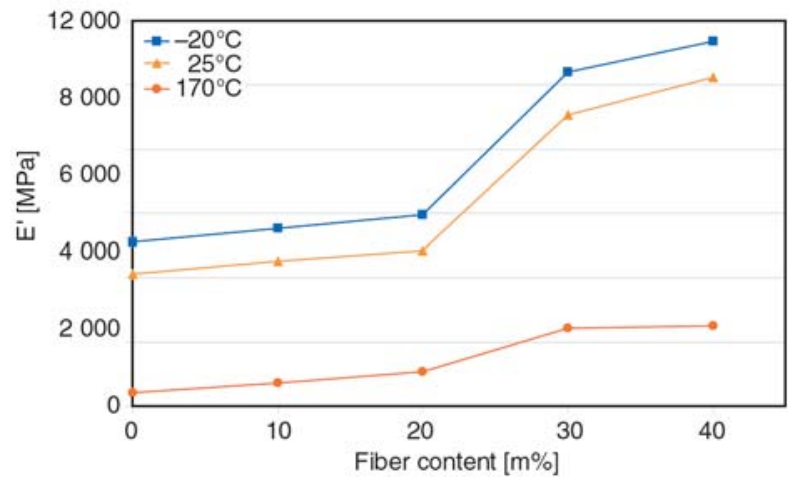

Figure 7. Storage moduli of composites with $4 \mathrm{wt} \%$ GF80 coupling agent at $-20,25$ and $170^{\circ} \mathrm{C}$ temperature as the function of fiber content

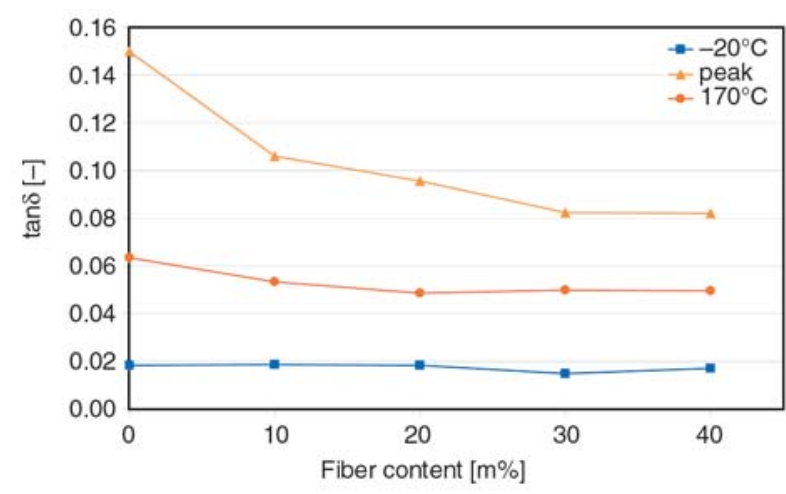

Figure 8. Loss factors of composites with 4 wt $\%$ GF80 coupling agent at $-20,25$ and $170^{\circ} \mathrm{C}$ temperature as the function of fiber content

advances that fiber reinforcement offers for high temperatures applications is also obvious: the storage modulus of $40 \mathrm{wt} \% \mathrm{BF}$ reinforced composite at $170^{\circ} \mathrm{C}$ is not lower than the $E^{\prime}$ of the matrix at room temperature. It can be concluded that DMA tests are suitable for assessing the quality of interfacial adhesion in PA matrix composites in a wide temperature range.

FTIR tests were performed on BF with GF80 coupling agent in order to prove the presence of the coupling agent on the surface of basalt fibers. The verification of the presence of coupling agents is possible by identifying atom groups which are in the coupling agents but can not be found in basalt [22]. The presence of coupling agents on the surface of fibers was proven in the wavenumber range between 2700 and $3100 \mathrm{~cm}^{-1}$. Figure 9 shows the spectrum of BF sized with different concentrations of GF80 silane. 'Calcinated' refers to the basalt fiber which were cleaned from sizing by annealing. The peaks at 2850 and $2925 \mathrm{~cm}^{-1}$ are in connection with $\mathrm{C}-\mathrm{H}$ bondings in aliphatic carbon chains. No distinct peaks can be seen on the curves of calci-

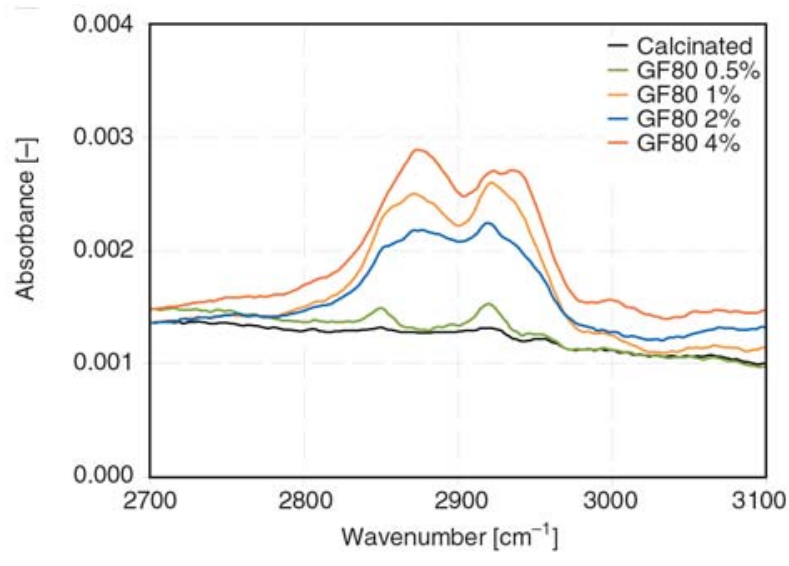

Figure 9. FTIR absorbance spectrum of basalt fibers sized with GF80 silane with different concentrations in the wavenumber range between 2700 and $3100 \mathrm{~cm}^{-1}$

nated BF. The height of peaks in Figure 9 shows some correlation with the concentration of GF80 silane, but it must be noticed that quantitative examinations are restrictedly possible by this method. FTIR tests proved the presence the GF80 coupling agent on the surface of BF, basically by detecting the $\mathrm{C}-\mathrm{H}$ bondings of the aliphatic carbon chains in the middle sections of silane molecules. The sufficient removal of the original sizing was also validated. It can be concluded that the presence of coupling agents on the BF was proven. However, the applied method could not confirm the formation of chemical bondings between the fibers and the coupling agents.

\section{Conclusions}

It was proven that silane coupling agents developed for glass fibers are applicable for basalt fibers. This is due to the approximately same structure and similar chemical composition of basalt and glass fibers. All three applied silane coupling agents influenced all investigated properties of the composites auspiciously. The optimum of concentration of coupling agents was not reached, among the given limits the application of $4 \mathrm{wt} \%$ of GF80 3-glycidoxypropyltrimethoxysilane gave the best results. In case of $30 \mathrm{wt} \%$ BF reinforced composites the tensile strength grew by $42 \%$, the flexural strength grew by $37 \%$ and the impact strength grew by $223 \%$ compared with unsized composite. The comprehensive DMA testing of composites and the matrix revealed that this method is suitable for assessing the quality of fiber-matrix interface of thermoplas- 
tic matrix composites in a wide temperature range, from deep below $0^{\circ} \mathrm{C}$ up to the vicinity of the melting temperature. The loss factor curves of DMA contain much information regarding the quality of interface. The peak height of $\tan \delta$ is particularly important, because it is in close relationship with the mobility of polymer molecular chain segments and side groups, hence it correlates with the number and strength of primary or secondary bondings established between the matrix and the BF. The $\tan \delta$ values can be compared in the entire temperature range. Their properties make basalt fiber reinforced PA matrix composite an engineering material which can be used in the industry in all fields where glass fiber reinforced composites have gained ground.

\section{Acknowledgements}

Kamenny Vek, Wacker and Arburg are kindly acknowledged for provision of the raw materials and supporting the work. This work was supported by Hungarian Scientific Research Fund (OTKA K61424 and NI62729).

\section{References}

[1] Botev M., Betchev A., Bikiaris D., Panayiotou C.: Mechanical properties and viscoelastic behavior of basalt fiber-reinforced polypropylene. Journal of Applied Polymer Science, 74, 523-531 (1999).

DOI: 10.1002/(SICI)1097-4628(19991017)74:3<523::

$$
\text { AID-APP7>3.0.CO;2-R }
$$

[2] Czigány T., Deák T., Tamás P.: Discontinuous basalt and glass fiber reinforced PP composites from textile prefabricates: Effects of interfacial modification on the mechanical performance. Composite Interfaces, 15, 697-707 (2008). DOI: $10.1163 / 156855408786778302$

[3] Hári J., Dominkovics Z., Fekete E., Pukánszky B.: Kinetics of structure formation in PP/layered silicate nanocomposites. Express Polymer Letters, 3, 692-702 (2009).

DOI: 10.3144/expresspolymlett.2009.87

[4] Lyons J. S.: Linear viscoelastic analysis of the roomtemperature creep behavior of glass-reinforced aromatic and aliphatic thermoplastics. Polymer Testing, 22, 545-551 (2003).

DOI: $10.1016 / \mathrm{S} 0142-9418(02) 00151-4$

[5] Kovács J. G., Solymossy B.: Effect of glass bead content and diameter on shrinkage and warpage of injection-molded PA6. Polymer Engineering and Science, 49, 2218-2224 (2009).

DOI: $10.1002 /$ pen. 21470
[6] Laura D. M., Keskkula H., Barlow J. W.: Effect of glass fiber surface chemistry on the mechanical properties of glass fiber reinforced, rubber-toughened nylon 6. Polymer, 43, 4673-4687 (2002). DOI: $\underline{10.1016 / \mathrm{S} 0032-3861(02) 00302-6}$

[7] Sui G., Wong S-C., Yue C-Y.: Effect of extrusion compounding on the mechanical properties of rubbertoughened polymers containing short glass fibers. Journal of Materials Processing Technology, 113, 167-171 (2001). DOI: 10.1016/S0924-0136(01)00627-6

[8] Deák T., Czigány T.: Chemical composition and mechanical properties of basalt and glass fibers: A comparison. Textile Research Journal, 79, 645-651 (2009).

DOI: $10.1177 / 0040517508095597$

[9] Zweifel H.: Plastics additives handbook. Hanser, München (2001).

[10] Kumar A., Gupta R. K.: Fundamentals of polymers. McGraw-Hill, New York (1998).

[11] Noda K., Tsuji M., Takahara A.: Aggregation structure and molecular motion of (glass-fiber/matrix nylon 66) interface in short glass-fiber reinforced nylon 66 composites. Polymer, 43, 4055-4062 (2002). DOI: $10.1016 / \mathrm{S} 0032-3861(02) 00200-8$

[12] Hull D.: An introduction to composite materials. Cambridge University Press, Cambridge (1981).

[13] Mészáros L., Tábi T., Kovács J. G.: The effect of EVA content on the processing parameters and the mechanical properties of LDPE/ground tire rubber blends. Polymer Engineering and Science, 48, 868-874 (2008).

DOI: $10.1002 /$ pen.21022

[14] Ragosta G., Musto P.: Polyimide/silica hybrids via the sol-gel route: High performance materials for the new technological challenges. Express Polymer Letters, 3, 413-428 (2009).

DOI: $10.3144 /$ expresspolymlett.2009.51

[15] Fritzsche J., Das A., Jurk R., Stöckelhuber K. W., Heinrich G., Klüppel M.: Relaxation dynamics of carboxylated nitrile rubber filled with organomodified nanoclay. Express Polymer Letters, 2, 373-381 (2008).

DOI: 10.3144/expresspolymlett.2008.44

[16] Kovács J. G.: Construction of pre-deformed shapes for rapid tooling in injection molding. Macromolecular Symposia, 239, 259-265 (2006). DOI: $10.1002 /$ masy.200690105

[17] Keszei S., Matkó Sz., Bertalan Gy., Anna P., Marosi Gy., Tóth A.: Progress in interface modifications: From compatibilization to adaptive and smart interphases. European Polymer Journal, 41, 697-705 (2005).

DOI: $\underline{10.1016 / j . e u r p o l y m j .2004 .10 .039}$ 
[18] Güllü A., Özdemir A., Özdemir E.: Experimental investigation of the effect of glass fibres on the mechanical properties of polypropylene (PP) and polyamide 6 (PA6) plastics. Materials and Design, 27, 316-323 (2006).

DOI: $10.1016 /$ j.matdes.2004.10.013

[19] Militký J., Kovacic V., Rubnerová J.: Influence of thermal treatment on tensile failure of basalt fibers. Engineering Fracture Mechanics, 69, 1025-1033 (2002).

DOI: $10.1016 / \mathrm{S} 0013-7944(01) 00119-9$
[20] Bernardo E., Stoll E., Boccaccini A. R.: Novel basalt fibre reinforced glass matrix composites. Journal of Materials Science, 41, 1207-1211 (2006).

DOI: $10.1007 / \mathrm{s} 10853-005-3658-0$

[21] Chou S., Lin L-S., Yeh J-T.: Effect of surface treatment of glass fibres on adhesion to phenolic resin. Polymers and Polymer Composites, 7, 21-31 (1999).

[22] Grellmann W., Seidler S.: Polymer testing. Hanser, München (2007). 